Published in final edited form as:

Harrington, M. J., Jehle, F., \& Priemel, T. (2018). Mussel byssus structure-function and fabrication as inspiration for biotechnological production of advanced materials. Biotechnology Journal, 13(12): 1800133. doi:10.1002/biot.201800133.

\title{
Mussel byssus structure-function and fabrication as inspiration for biotechnological production of advanced materials
}

Matthew J. Harrington, Franziska Jehle, Tobias Priemel

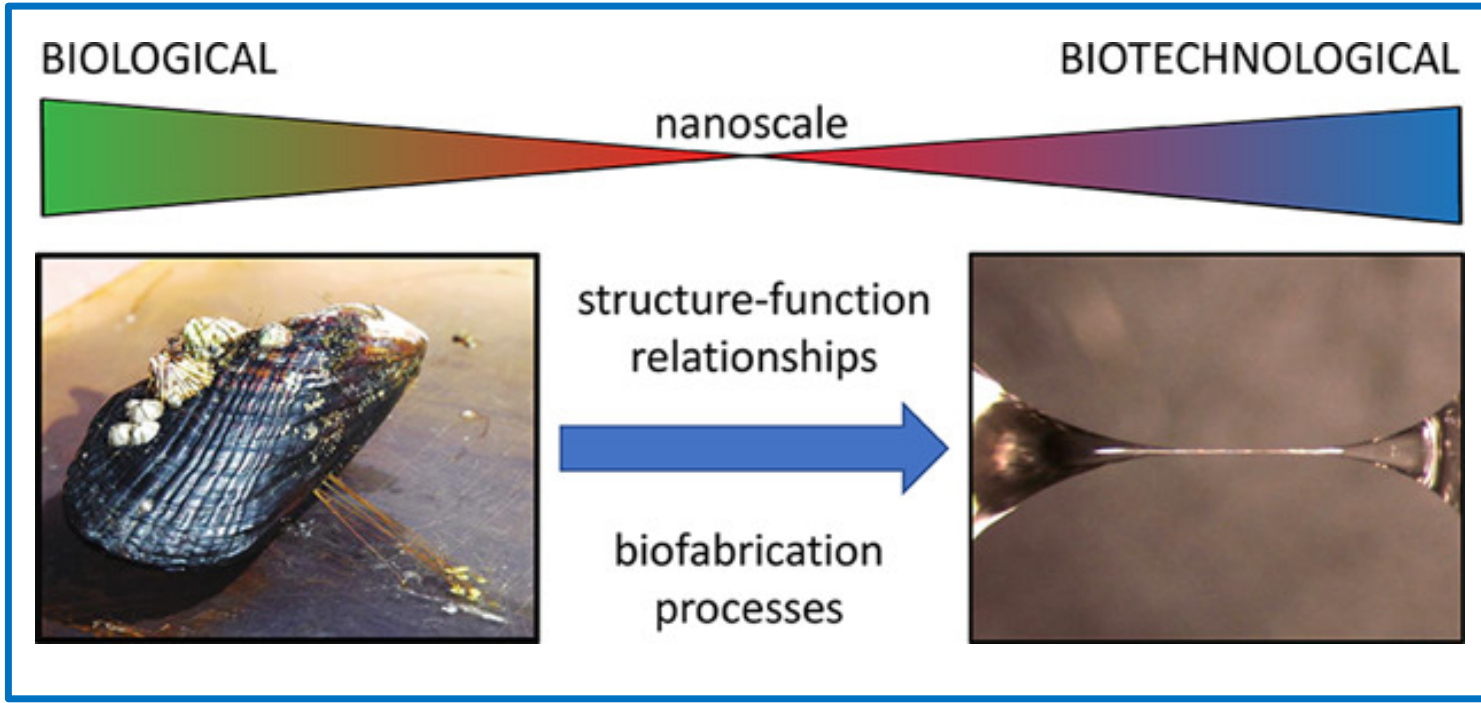

Protein-based materials produced by biological organisms from protein building blocks are important archetypes for future development of sustainable, advanced materials, and biotechnology offers great potential as a translational technology. Herein are reviewed relevant extracted design principles from the structure-function relationships and fabrication of the mussel byssus - a collection tough and self-healing adhesive biofiber produced by mussels. Recent progress in biotechnological production of musselinspired materials is highlighted.

This article may be used for non-commercial purposes in accordance with Cell Press Terms and Conditions for Self-Archiving. 


\section{Review}

Mussel byssus structure-function and fabrication as inspiration for biotechnological production of advanced materials ${ }^{\dagger}$

Matthew J. Harrington ${ }^{1,2}$

Franziska Jehle ${ }^{1}$

Tobias Priemel ${ }^{2}$

${ }^{1}$ Dept. of Biomaterials, Max Planck Institute of Colloids and Interfaces, Potsdam 14424, Germany

${ }^{2}$ Dept. of Chemistry, McGill University, 801 Sherbrooke Street West, Montreal, Quebec H3A 0B8, Canada

Correspondence: Matthew J. Harrington, Dept. of Chemistry, McGill University, 801 Sherbrooke Street

West, Montreal, Quebec H3A 0B8, Canada

E-mail: matt.harrington@mcgill.ca

Keywords: byssus, bio-inspired, metal coordination, DOPA, collagen,

Abbreviations: DOPA, 3,4-dihydroxyphenylalanin; HRD, histidine-rich domain; SAXD, small-angle X-ray diffraction; WAXD, wide-angle X-ray diffraction; XAS, X-ray absorption spectroscopy 


\begin{abstract}
Biotechnology offers an exciting avenue towards the sustainable production of high performance proteinaceous polymeric materials. In particular, the mussel byssus - a high performance adhesive biofiber used by mussels to cling on hard surfaces - has become a veritable archetype for bio-inspired selfhealing fibers, tough coatings and versatile wet adhesives. However, successful translation of musselinspired design principles into man-made materials hinges upon elucidating structure-function relationships and biological fabrication processes. In the present review, we provide a detailed survey of the state-of-the-art understanding of the biochemical structure-function relationships defining byssus performance with a particular focus on structural hierarchy and metal coordination-based cross-linking. We then discuss efforts to mimic the byssus in man-made materials. While there has been a strong push to mimic the byssus via synthetic chemistry taking a reductionist approach, here we focus specifically on recent progress of biotechnology-based strategies that more closely approximate the biochemical complexity of the natural material. As an outlook, we provide an overview of recent research towards understanding the natural byssus assembly process, as processing remains a critical factor in achieving native-like properties.
\end{abstract}




\section{Introduction}

Organisms such as silkworms, spiders, mussels and velvet worms fabricate high performance biopolymeric fibers from proteins outside their bodies, exhibiting mechanical properties rivaling those of the best manmade polymers [1-4]. For example, spider silk and mussel byssus possess a toughness comparable to Kevlar, an advanced polymer fiber utilized in ballistic panels [2]. Moreover, while the polyaramid precursor of Kevlar requires nearly pure sulfuric acid to dissolve at $80^{\circ} \mathrm{C}$ [5], these bio-degradable proteinbased fibers are created under ambient conditions, offering inspiration for green and sustainable material processing achieved through biotechnology.

Analogous to silk, the mussel byssus is a high-performance fibrous material that has emerged as a role model for bio-inspired materials including wet adhesives, self-healing materials and tough coatings with technical and biomedical applications [3, 6-8]. Mussels use byssal threads to adhere and anchor to surfaces on the rocky seashore [9]. Byssal threads can stick to a wide range of different surface chemistries, functioning to dissipate enormous mechanical forces from crashing waves [9]. There is now an excellent understanding of the complex relationship between the structural organization of the byssal proteins (of which there are 10 or more $[9,10]$ ) and the mechanical performance. Initial efforts to mimic byssus properties via synthetic chemistry have focused on the distinctive metal-coordination chemistry in threads [11], resulting in self-healing hydrogels, polymer coatings and even surgical adhesives [6-8]. Yet, these materials largely lack the structural and mechanical complexity of the native byssus due to this reductionist strategy. Alternatively, similar efforts using biotechnology more closely mimic the natural protein sequences and conformation and more closely follow the native assembly process to achieve greater control over material structure and thus, properties. In this review, we discuss the defining structure-function relationships of the mussel byssus and the ongoing efforts to adapt material design principles extracted from the byssus into materials via biotechnology. We conclude with an overview of 
the current understanding of byssus processing and self-assembly, which is critical to realizing native-like function.

\section{Structure-function relationships in the byssus}

\subsection{Morphology and function}

A typical byssus from marine mussels (Mytilus spp.) possesses $50-100$ byssal threads. Each thread is approximately $2-5 \mathrm{~cm}$ long and further subdivided into three structurally and functionally distinct parts known as the plaque, core and cuticle (Fig. 1A-B). The plaque is a versatile underwater adhesive glue that serves as the interface between the byssal thread and the surface [12]. The core of the thread is a fibrous bio-polymer anchored into the plaque that provides the energy-damping function $[13,14]$. The cuticle is a thin sheath surrounding the core and plaque proposed to function as a protective coating [15]. Below, we discuss the core, cuticle and plaque separately, providing a brief review of multiscale structurefunction relationships.

\subsection{Byssus core}

The fibrous core of a byssal threads is believed to primarily determine its tensile mechanical properties $[13,14,16,17]$. Threads have two distinct regions known as the distal and proximal thread, which are adjacent to the surface and mussel, respectively. These two regions differ morphologically and mechanically with the distal region exhibiting a fibrous morphology and the proximal exhibiting a corrugated structure [14]. While the distal region is characterized by a species-dependent stiffness of up to $800 \mathrm{MPa}$ and extensibility of $\sim 100 \%$, the proximal region has a ten-fold lower stiffness and twice the extensibility $[14,18]$. The combination of high strength and extensibility in the distal region results in a toughness exceeding most synthetic polymers [2], as well as a large hysteresis ( 70\%). Most notably, threads are able to recover initial properties following cyclic loading in spontaneous self-healing process $[14,19]$, which is highly desirable from a biomimicry standpoint. 

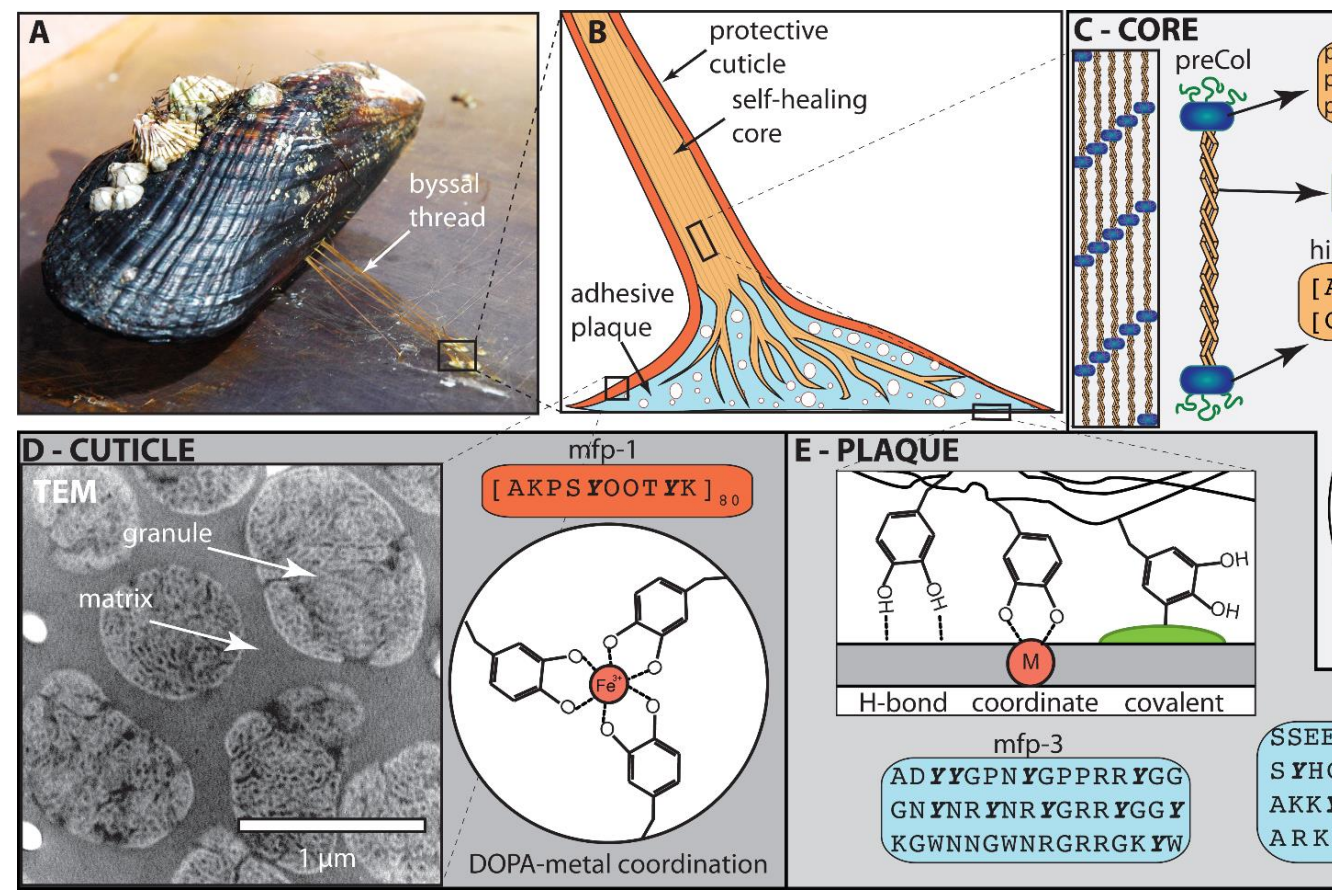

flanking domain preCol-D = silk-like preCol-P = elastin-like preCol-NG = Gly-rich collagen domain $[\mathrm{GXY}]_{300}$ $X \& Y=$ Pro, Hyp histidine-rich domain [ AVAHAHAHAHASAGA ] [ GHGGGHGGGHGGGHG ]

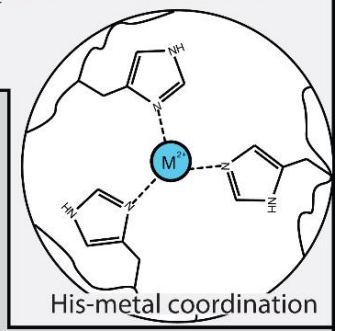

$\mathrm{mfp}-5$ SSEE YKGG Y YPGNA YH YSGG S $\boldsymbol{Y H G ~ S ~ G ~} \boldsymbol{Y H}$ GG $\boldsymbol{Y K G K} \boldsymbol{Y} \boldsymbol{Y G K}$ AKK $Y Y Y K Y K N S G K Y K Y L K K$ A R K $Y$ H R K $Y$ K $Y Y$ G G S S

Figure 1

Figure 1. Structural hierarchy of the mussel byssus. A) Mussels anchor on surfaces with a byssus.

B) Individual byssal threads are comprised of a shock-absorbing fibrous core, sheathed by a thin protective cuticle and ending in underwater adhesive plaque. C) The core is comprised of collagenous modular proteins, known as preCols, which are organized into a semicrystalline framework and stabilized by histidine-metal coordination bonds. D) The cuticle, which resembles particle reinforced composite, is comprised mainly of a repetitive DOPA-rich protein, $\mathrm{mfp}-1$, which is cross-linked via metal coordination bonds with Fe3+. E) Plaque adhesion is mainly mediated by DOPA and Lys-rich proteins mfp-3 and mfp-5, which utilize DOPA to create a range of interactions with surfaces. In protein sequences above, bold, italicized $Y$ signifies DOPA. 
The core is comprised of a family of modular collagenous proteins called preCols (Fig. 1C) [20]. The central preCol domain possesses a [Gly-X-Y] $]_{n}$ repeat sequence typical of fibrillar collagen ( $X$ and $Y$ are often proline or hydroxyproline). Surrounding the collagen domain are the flanking domains, which are distinctive between the three identified preCol variants. PreCol-D (found in the distal end) has dragline silk-like flanking domains with polyalanine runs and glycine-rich spacers, preCol-P (found in proximal end) has a hydrophobic sequence reminiscent of elastin, and preCol-NG (uniformly distributed) has a glycine-rich sequence resembling extensible domains from flagelliform silk [20]. At the $\mathrm{N}$ - and C-termini of all preCols are histidine rich domains (HRDs), which contain $\sim 20$ mol\% histidine interspersed [20]. In addition to preCols, the thread matrix proteins comprise $\sim 2 \%$ of the thread composition in the distal (TMP-1) and 35\% in the proximal (PTMP-1) and are believed to play a role in assembly and fibrillation [21-23].

X-ray diffraction and spectroscopic investigations of threads have established a consistent model for the conformation and higher order organization of preCols in the distal thread $[13,16,19,24,25]$. Wide-angle X-ray diffraction (WAXD) investigations confirmed the presence of collagen triple helices similar to type I collagen, but also clearly identified the presence of $\operatorname{cross} \beta$-sheet structure arising from preCol-D flanking domains [13, 19] - an assignment supported by FTIR spectroscopy [25] and NMR investigations [24]. Small angle X-ray diffraction (SAXD) studies further revealed that preCol triple helices are organized into $6+1$ hexagonal bundles (Fig. 1C), arranged in a semi-crystalline hierarchical structure $[13,16]$.

End-to-end linkage of preCol bundles is mediated by the HRDs via both covalent bonding and metal coordination interactions between histidine residues and $\mathrm{Zn}^{2+}$ (Fig. 1C) [17, 26]. Coordination bonds consist of several histidine ligands, which donate a lone pair of electrons into empty outer shell hybrid orbitals of the transition metal ion [11]. Coordination bonds possess properties between covalent bonds and non-covalent bonds with an intermediate bond strength and an increased lability in terms of bond exchange. X-ray absorption spectroscopy (XAS) results confirmed the presence of protein-Z $\mathrm{n}^{2+}$ complexes in native byssal threads mediated, on average, by three histidine residues and one aspartate residue [17]. 
XRD and FTIR performed during in situ mechanical testing revealed that preCol collagen domains do not extend appreciably during loading, whereas preCol-D flanking domains unfold to large extensions and refold on very short time scales $[13,16,19,25]$. The beta sheet structure, therefore, provides a source of reversible hidden length due to its highly compact folded structure, contributing to extensibility. However, XAS investigations indicate that sacrificial His-metal coordination bonds rupture first, providing the high stiffness and strain energy during cyclic loading [17]. Current models indicate that self-healing arises from re-formation and exchange of broken metal coordination bonds towards a native-like cross-link network, leading to recovery of stiffness [17]. Thus, byssus core mechanical performance depends on the hierarchical organization of protein building blocks and cross-links at multiple length scales.

\subsection{Byssus cuticle}

Surrounding the extensible core is a thin $(5-10 \mu \mathrm{m})$, bumpy layer known as the cuticle (Fig. 1D). Mechanically, the cuticle is stiffer and harder than the core, with values comparable to engineering epoxies [15]. Surprisingly, in spite of the high hardness and stiffness, the cuticle is highly extensible, which is remarkable since hard materials are typically not stretchy. Thus, the cuticle could inspire novel engineering polymers for extensible coatings in applications such as flexible electronics and biomedical devices.

Currently, only one protein is confirmed in the cuticle - mussel foot protein (mfp)-1. However, recently transcriptomic analysis has identified other possible candidates [10]. Mfp-1 is a repetitive protein consisting of $\sim 80$ tandem repeats of a highly conserved decapeptide sequence (Fig. 1D). Different species have slightly different sequences, but always exhibit a basic isoelectric point (pl) due to the prevalence of lysine and contain highly conserved Tyr residues, most of which are enzymatically modified to 3,4dihydroxyphenylalanine (DOPA) [7]. Mfp-1 is largely unstructured based on spectroscopic analysis [27]. However, nanostructural analysis of the cuticle indicates a clear higher order organization consisting of spherical granular regions ( $500-1000 \mathrm{~nm}$ ) with a brain-like texture embedded in an amorphous matrix 
(Fig. 1D) $[15,28]$. Currently, not much is understood about the role of this unusual structure; however, previous studies revealed that the matrix appears to deform more than the embedded granules, suggesting different stiffness [15]. In addition to proteins, the cuticle contains elevated content of metal ions such as iron, vanadium and aluminum [29]. Confocal Raman spectroscopic imaging of the cuticle revealed the presence of DOPA-Fe and DOPA-V metal coordination bonds localized in the cuticle and further showed that, compared to the matrix, granules possess twice the DOPA-metal cross-link content (Fig. 1D) $[28,29]$. Removal of metals via chelation resulted in an $>80 \%$ reduction in material stiffness and hardness, while soaking metal-depleted threads in solutions of $\mathrm{FeCl}_{3}$ and $\mathrm{VCl}_{3}$ resulted in full recovery of material performance [29], strongly supporting a model in which DOPA-metal coordination contributes to the hard, yet extensible properties of the cuticle.

\subsection{Byssus Plaque}

The byssus plaque has received the most attention from researchers wishing to replicate its remarkable ability to adhere to almost any surface chemistry in salty seawater environments, which has obvious biomedical and industrial relevance [7]. Bound water, ionic double layers and biofilms present numerous challenges for wet adhesion; yet, mussels have evolved a protein-based mechanism to circumvent this [7, 12]. Spearheaded by the Waite group, nearly forty years of research have gone into unraveling the complex adhesive mechanism in Mytilus spp. mussels, resulting in a very detailed understanding of the biochemistry behind their stickiness [12]. The plaque consists of at least five proteins, although several more putative candidates were recently identified via transcriptomics [10]. The main players at the adhesive interface between plaque and surface are the proteins mfp-3 and mfp-5 (Fig. 1E), both of which are small, DOPA and Lys-rich proteins. The interaction of $\mathrm{mfp}-3$ and $\mathrm{mfp}-5$ with various surfaces has been intensively studied using a technique called surface force apparatus (SFA), which measures work of adhesion for monolayers of biomolecules. Using SFA on different surfaces, it was determined that mfp-3 and -5 create strong interactions primarily mediated with DOPA, which interact via hydrogen bonds, 
hydrophobic interactions, metal coordination and covalent cross-linking depending on the surface chemistry presented and the local conditions (Fig. 1E) [12, 30]. DOPA's known tendency to oxidize at seawater $\mathrm{pH}$ to the quinone form, which tends to form covalent cross-links and is less efficient at adhesion $[7,12,31]$, is counteracted by a cysteine-rich protein, $\mathrm{mfp}-6$, which functions as an effective reducing agent [32]. Additionally, it was recently proposed that Lys residues in the adhesive proteins displace cations in the electrical double layer on metal oxide surfaces, clearing the way for DOPA adhesion [33]. More recently, evidence has emerged that DOPA and other aromatic residues in plaque proteins may also participate in cohesive cation-pi interactions with positively charged side groups of lysine and arginine during the formation and function of the byssus plaque $[12,34,35]$. The biochemical subtleties inherent to mussel adhesion have great potential for inspiring synthetic underwater glues.

\section{Mussel-inspired materials}

Based on the structure-function relationships described above, many groups have attempted to transfer extracted design principles from the byssus into man-made materials. However, due to the underlying complexity of the natural system, this is easier said than done. While traditional polymers are produced from long chains with repeating monomeric subunits, protein function is determined by specific sequences of amino acids with defined length presenting side chains with different chemical properties. The sequence and length of the proteins determined by natural selection are intimately linked to the higher order hierarchical structure of the materials, which largely determine material properties.

Initial efforts to produce mussel-inspired materials took a minimalist approach, reducing the complexity of the byssal proteins to single amino acid moieties [36, 37]. In particular, there has been a strong focus on harnessing metal coordination chemistry mediated via Histidine and DOPA moieties towards synthetic production of wet adhesives and self-healing materials [6-8, 36-39]. This reductionist synthetic approach has been highly successful; however, the details are well reviewed elsewhere [6-8] and lie outside the scope of the current review. Rather, we focus here on discussing biotechnological efforts to produce new 
materials from protein and peptide building blocks. As summarized in Table 1, we discuss this research in terms of three categories: 1) materials from purified proteins 2) bio-based production of materials from recombinant proteins and 3) materials from synthetic peptides. Indeed, investigations of the native byssus reveal, if anything, that the desirable material properties are not just the result of a single functional group, but rely on the complex interplay with other residues and hierarchical architecture. Biotechnological processes are promising for production of sustainable polymers under ambient conditions and permit closer mimicry of the complexity inherent in the native system, leaving the functional groups in the context of their natural chemical and structural protein environment.

\subsection{Materials from extracted byssus proteins}

The potential of a biotechnological approach for mussel-inspired materials was demonstrated over a decade ago with purified proteins from the byssus and mussel soft tissue, including mfp-1 and the preCols. For example, preCols extracted and purified from mussel foot tissue of Mytilus californianus were easily drawn into fibers with ultrastructure and mechanical properties reminiscent of native byssal threads (Fig. 2A) $[40,41]$. A drawback of this approach was the very low protein yield-only $1 \mathrm{mg}$ from 30 mussel feet. Alternatively, several groups utilized both basic and acidic partial hydrolysis of crude byssus that resulted in larger amount of relatively impure fibrous byssus material, which could be formed into free-standing water-insoluble films with fibrillar structure and tunable properties [42-45]. Additionally, Cell-Tak ${ }^{\mathrm{TM}}$, a formulated protein solution extracted from mussels containing mfp-1 is marketed as a natural adhesive for attaching cells or sections of tissue to a wide range of surfaces. However, mfp-1 faces a similar problem to preCol of inefficient extraction and purification yields [46]. Based on methods developed by Waite and co-workers, it is possible to extract and purify many of the byssus adhesive proteins including mfp- 3 and $5[47,48]$. Dependent on ionic strength and $\mathrm{pH}$, purified mfp-3 is able to form self-coacervates - a liquidliquid phase separation proposed to be critical to the formation of the adhesive interface due to low interfacial energy and high density $[12,49]$. However, the extraction of mfp-3 from mussel feet, like preCol 
Table 1. Mussel-inspired materials achieved through biotechnology.

\begin{tabular}{|c|c|c|c|c|c|}
\hline & $\begin{array}{l}\text { mussel thread } \\
\text { protein }\end{array}$ & $\begin{array}{l}\text { recombinant/peptide } \\
\text { version }\end{array}$ & $\begin{array}{l}\text { resulting } \\
\text { material }\end{array}$ & properties & ref. \\
\hline \multirow{3}{*}{$\begin{array}{l}\text { purified } \\
\text { thread } \\
\text { proteins }\end{array}$} & preCols & NA & $\begin{array}{l}\text { hand-drawn } \\
\text { fiber }\end{array}$ & $\begin{array}{l}\text { similar structure and properties to } \\
\text { native threads. } E=71 \mathrm{MPa} ; \sigma_{\text {ult }}= \\
40 \mathrm{MPa} ; \varepsilon_{\text {ult }}=107 \%\end{array}$ & {$[40]$} \\
\hline & $\begin{array}{l}\text { byssal thread } \\
\text { hydrolysate }\end{array}$ & NA & $\begin{array}{l}\text { water- } \\
\text { insoluble films }\end{array}$ & $\begin{array}{l}\text { pH-tunability; dye removal. } \mathrm{E}=10 \\
\mathrm{MPa} ; \sigma_{\text {ult }}=2.5 \mathrm{MPa}\end{array}$ & {$[43,44]$} \\
\hline & $m f p-3$ & NA & $\begin{array}{c}\text { self- } \\
\text { coacervate }\end{array}$ & $\begin{array}{l}\text { dependent on } \mathrm{pH} \text { and ionic } \\
\text { strength }\end{array}$ & [49] \\
\hline \multirow{15}{*}{$\begin{array}{l}\text { recombinant } \\
\text { thread } \\
\text { proteins }\end{array}$} & preCol-D & preCol-D & nanofibrils & $\begin{array}{l}\text { defined secondary structure, } \\
\text { presence of triple helices }\end{array}$ & {$[50]$} \\
\hline & ptmp-1 & ptmp-1 & adhesive & $\begin{array}{l}\text { enhancing mouse osteoblast cell } \\
\text { adhesion, collagen interaction }\end{array}$ & {$[51]$} \\
\hline & $m f p-1$ & $\mathrm{rfp}-1$ & $\begin{array}{l}\text { surface } \\
\text { coating }\end{array}$ & $\begin{array}{l}\mathrm{Fe}^{3+} \text { mediated bridging. } \mathrm{W}_{\mathrm{ad}}=5.7 \\
\mathrm{~mJ} / \mathrm{m}^{2}\end{array}$ & {$[54]$} \\
\hline & $\mathrm{mfp}-1$ & $\mathrm{rfp}-1$ & $\begin{array}{l}\text { adhesive } \\
\text { hydrogel }\end{array}$ & $\begin{array}{l}\text { flexible viscoelastic and self- } \\
\text { healing behavior }\end{array}$ & {$[53]$} \\
\hline & $\mathrm{mfp}-1$ & $\mathrm{rfp}-1$ & $\begin{array}{c}\text { polymeric } \\
\text { nanoparticles }\end{array}$ & $\begin{array}{l}\mathrm{pH} \text {-responsive anti-breast-cancer } \\
\text { drug release }\end{array}$ & {$[52]$} \\
\hline & $\mathrm{mfp}-1$ & $\mathrm{rfp}-1$ & coacervate & $\begin{array}{l}\text { cation- } \boldsymbol{\pi} \text { stabilized. } \mathrm{W}_{\mathrm{ad}}=4.8 \\
\mathrm{~mJ} / \mathrm{m}^{2}\end{array}$ & {$[55]$} \\
\hline & $\mathrm{mfp}-1$ & $\mathrm{rfp}-1$ & $\begin{array}{c}\text { self- } \\
\text { coacervate }\end{array}$ & salt-triggered. $W_{a d}=5.0 \mathrm{~mJ} / \mathrm{m}^{2}$ & {$[35]$} \\
\hline & $m f p-5$ & $\mathrm{rfp}-5$ & adhesive & $\begin{array}{l}\text { suitable for cell biological } \\
\text { applications }\end{array}$ & {$[56]$} \\
\hline & $\mathrm{mfp}-5$ & $\mathrm{rfp}-5$ & adhesive & immobilization of antibodies & {$[57]$} \\
\hline & mfp-1, mfp-5 & $f p-151$ & adhesive & greater production yields & {$[59]$} \\
\hline & $m f p-1, m f p-5$ & $f p-151$ & adhesive & improved purification & {$[58]$} \\
\hline & $m f p-1, m f p-5$ & $f p-151$ & $\begin{array}{l}\text { composite } \\
\text { nanofibers }\end{array}$ & $\begin{array}{l}\text { scaffold for bio-active molecules. } \\
\mathrm{E}=44 \mathrm{MPa} ; \sigma_{\text {ult }}=18 \mathrm{MPa} ; \varepsilon_{\text {ult }}= \\
107 \%\end{array}$ & {$[60]$} \\
\hline & $m f p-1, m f p-5$ & fp-151-RGD & adhesive & $\begin{array}{l}\text { superior cell-adhesion and } \\
\text { spreading abilities }\end{array}$ & {$[61]$} \\
\hline & $m f p-1, m f p-5$ & fp-151-peptide & adhesive & $\begin{array}{l}\text { enhanced adhesion, proliferation } \\
\text { and spreading of mammalian cells }\end{array}$ & {$[62]$} \\
\hline & $\begin{array}{l}\mathrm{mfp}-1, \mathrm{mfp}-3 \\
\mathrm{mfp}-5\end{array}$ & $\begin{array}{l}\mathrm{fp}-131 \\
\mathrm{fp}-151\end{array}$ & $\begin{array}{c}\text { complex } \\
\text { coacervate }\end{array}$ & enhanced adhesive strength & {$[63]$} \\
\hline \multirow{3}{*}{$\begin{array}{l}\text { mussel- } \\
\text { inspired } \\
\text { peptides }\end{array}$} & preCol-D & HRD-DN & $\begin{array}{l}\text { free-standing } \\
\text { films }\end{array}$ & $\begin{array}{l}\text { metal-tunable architecture and } \\
\text { mechanics. } \mathrm{E}=3.5 \mathrm{MPa}(\mathrm{w} / \mathrm{o} \\
\text { metals; } 23 \mathrm{MPa}\left(\mathrm{w} / \mathrm{Zn}^{2+}\right)\end{array}$ & {$[65]$} \\
\hline & $\mathrm{mfp}-3$ & mfp-3S-pep & $\begin{array}{l}\text { coacervate } \\
\text { adhesive }\end{array}$ & $\begin{array}{l}\text { improved adsorption kinetics and } \\
\text { quantity }\end{array}$ & {$[67]$} \\
\hline & $\mathrm{mfp}-5$ & $\begin{array}{l}\text { PEP-pl-4, PEP-pl-6.5, } \\
\text { PEP-pl-10, PEP-pl-4- } \\
\text { dimer }\end{array}$ & adhesive & $\begin{array}{l}\text { enhanced adhesion via amino acid } \\
\text { synergy }\end{array}$ & {$[68]$} \\
\hline
\end{tabular}

$\mathrm{E}=$ stiffness $; \sigma_{\text {ult }}=$ strength $; \varepsilon_{\text {ult }}=$ extensibility; $\mathrm{W}_{\mathrm{ad}}=$ work of adhesion 
and mfp-1, is labor-intensive and produces low yields, making it impractical for mass-production of bioinspired adhesives.

\subsection{Materials from recombinant byssus proteins}

Recombinant approaches offer promise towards producing higher yields of byssus proteins. Efforts to produce preCols in bacteria have met numerous challenges due to the high degree of post-translational modification (hydroxyproline is critical for the collagen stability); however, by using Pichia pastoris as an expression host, Scheibel and co-workers successfully produced preCol-D recombinantly [50]. Similar to preCol extracted from mussel foot tissue, it formed nanofibrils under native conditions; however, this approach currently suffers from the similar low yields of native extraction and needs to be optimized. It has also been possible to recombinantly express the two matrix proteins present within the fibrous core, tmp-1 and ptmp-1 $[21,23]$. It was proposed that both proteins influence the mechanical properties of byssal threads via their direct interactions with preCols $[21,22]$. Studies with recombinant ptmp-1 demonstrated that the matrix protein mediated via von Willebrand type-A like domains is able to enhance mouse osteoblast cell adhesion and interact with type I collagen, reinforcing its role in thread assembly and function and its potential use as a biomedical adhesive [51].

Mfp-1, like other byssus proteins, possesses a highly repetitive protein sequence, resulting in a biased amino acid composition that, during recombinant expression, can inhibit cell growth or cause formation of inclusion bodies, leading to low recombinant product yields. In addition, the heavy post-translational modification of mfp-1 (e.g. hydroxylysine and DOPA) presents an additional problem, as DOPA plays an essential role in protein function [12, 31]. A strategy to circumvent the inherent challenge of expressing very long and repetitive proteins is the biotechnological production of a shortened construct, in which tyrosine residues are modified to DOPA enzymatically in vitro following expression. For example, rfp-1, a truncated variant of mfp-1 comprising only 12 tandemly repeated decapeptides (AKPSYPPTYK) 12 was successfully produced and exploited in several studies [52-54]. Following enzymatic modification of Tyr to 
DOPA, $\mathrm{Fe}^{3+}$ could mediate strong bridging of $\mathrm{rfp}-1$ coated surfaces via DOPA-iron complexation [54]. A potential medical adhesive and sealant based on rfp-1 was developed in which gelation of concentrated rfp-1 solution was mediated either by noncovalent $\mathrm{Fe}^{3+}$ complexation or quinone-mediated covalent cross-linking [53], resulting in tunable viscoelastic and self-healing behavior. The pH sensitivity of the DOPA-Fe ${ }^{3+}$ complex was exploited to develop an electrospraying process to synthesize polymeric nanoparticles based on rfp-1 and doxorubicin, a commercial anti-breast-cancer drug, in which drug release was induced via pH-dependent changes in DOPA-metal coordination (Fig. 2B) [52]. The nanoparticles were efficiently taken up by cells and drug release resulted in a cytotoxic effect on the cancer cell line. Additionally, truncated versions of mfp-1 were used to investigate the role of charge in the mechanism underlying complex coacervation of byssal thread proteins $[35,55]$.

Based on their role in adhesion, $\mathrm{mfp}-3$ and $\mathrm{mfp}-5$ have become attractive targets for biotechnological production of underwater glues (e.g. for biomedical applications), especially as they are biocompatible and biodegradable. The biotechnological production of $\mathrm{mfp}-5$ was reported more than ten years ago and used as a bio-adhesive for cell biological applications [56]. By fusing recombinant mfp-5 with two domains of an antibody-binding protein, it was also possible to immobilize antibodies onto surfaces [57]. To address issues of protein yield, a novel fusion protein $\mathrm{fp}-151$ was developed with six mfp-1 decapeptide repeats at each terminus of $\mathrm{mfp}-5$, exhibiting significantly greater yields and the potential to be used as a tissue bio-adhesive and even an electrospun scaffold for biomedical applications (Fig. 2B) [58-60]. To further promote the potential of fp-151 in the biomedical arena, an RGD cell-adhesion recognition motif was fused with the C-terminus resulting in improved cell-adhesion and spreading abilities [61]. Other extracellular matrix (ECM) peptides stemming from fibronectin, laminin and type IV collagen were also fused to $\mathrm{fp}-151$, demonstrating the potential of this approach for adhesives for cell culture and tissue engineering [62]. The potential role of complex coacervation in mfp-3 and $\mathrm{mfp}-5$ mediated adhesion was also investigated using $\mathrm{fp}-151$, as well as $\mathrm{fp}-131$, a recombinant protein containing six decapeptides of 

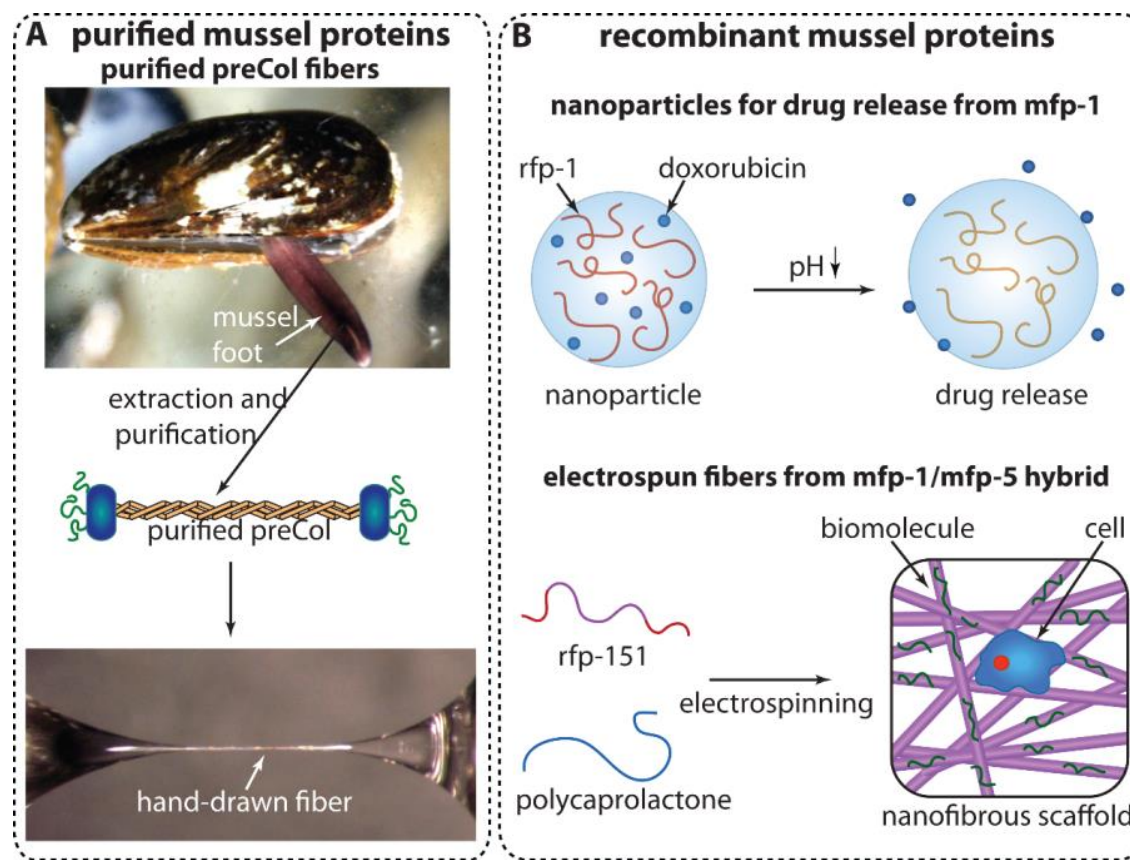

electrospun fibers from $\mathrm{mfp}-1 / \mathrm{mfp}-5$ hybrid
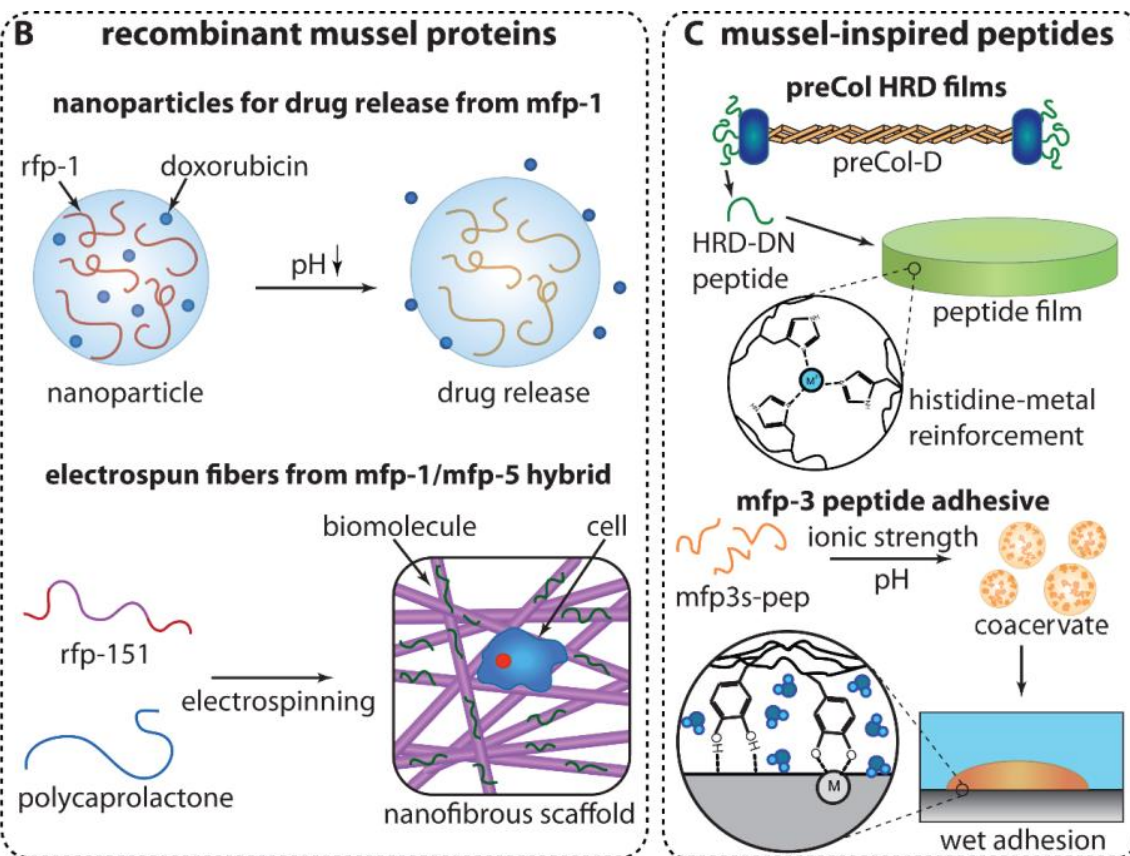

mfp-3 peptide adhesive

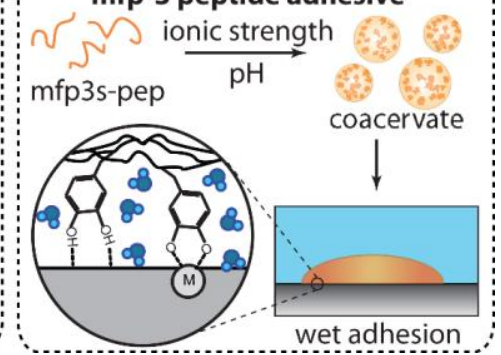

Figure 2. Mussel-inspired materials via biotechnology. A) PreCols purified from mussel foot tissue were drawn into anisotropic fibers with native-like properties [40]. B) Nanoparticles based on recombinant mfp1 were used for $\mathrm{pH}$-induced drug release [52], while rfp-151, a recombinant fusion mfp-1 and mfp-5, was electrospun into nanofibers with polymer-blending partners and can serve as a scaffold for bioactive molecules and cell growth [60]. C) Peptides based on preCol His-rich domains self-assemble into freestanding peptide-films, the hierarchical architecture and mechanics of which can be tuned with metal ions [65]. A peptide based on mfp-3 self-coacervates, promoting adhesion on wet surfaces [67]. 
mfp-1 at both termini of mfp-3 [63]. By using hyaluronic acid as an anionic counterpart both formed complex coacervates, which enhanced the adhesive strength of the material approximately two-fold. In an effort to circumvent challenges involved in the efficiency of enzymatic post-translational modification of tyrosine to DOPA in recombinant mussel proteins, researchers have also been able to incorporate DOPA during recombinant expression via misaminoacylation of DOPA to the tyrosine tRNA [64]. This resulted in a higher DOPA content compared with enzymatic methods and a concomitant increase in adhesive properties.

\subsection{Materials from byssus peptides}

An alternative approach to recombinant expression is peptide synthesis, in which short stretches of protein sequence (less than 40 amino acids) are utilized. Peptides allow a more minimalist approach that still leaves functional amino acid groups in the relevant biochemical context of their native sequence. For example, several peptide-based studies investigated the preCol histidine-rich domains (HRDs), with a specific focus on their role in $\mathrm{pH}$-dependent self-assembly and mechanical performance of threads [11, $17,20]$. Inspired by the natural assembly process, HRD peptides based on the $\mathrm{N}$-terminal histidine-rich domain of preCol-D (HRD-DN) were investigated and formed into free-standing films both in the absence and presence of metal ions, demonstrating tunability of both the higher order structure and mechanical properties of the films (Fig. 2C) [65, 66]. Similarly, short, but representative regions of mfp-3 were harnessed to elucidate the role of amino acids other than DOPA in coacervation and adhesion [67]. Although shorter, the resulting peptide possessed the main characteristics with abundant positively charged and aromatic residues. To shed light on DOPA's role in adhesion and coacervation, peptides with modified and unmodified Tyr were investigated. Notably, the DOPA-modified peptide formed a singlecomponent coacervates promoting faster initial adsorption kinetics and enhanced adsorption (Fig. 2C)

[67]. A similar approach using different peptides based on $\mathrm{mfp}-5$ in which tyrosine residues were enzymatically modified to DOPA demonstrated that synergistic effects between amino acids over the 
whole protein sequence are crucial for the strong adhesion of mfp-5 [68]. Taken together, these studies demonstrate that mussel-inspired peptides can be a valuable alternative to recombinant full-length constructs when addressing specific research questions.

\section{Byssus bio-fabrication}

As described above, there has been a great deal of progress in the development of mussel-inspired materials and adhesives in the last 15 years, both through synthetic chemistry and biotechnological means. However, as of yet, these materials do not match the performance of the biological role model, which likely originates from the lack of structural hierarchy and chemical complexity that defines the native byssus. Breakthroughs in achieving hierarchical structure in artificial spider silk spinning and thus, native-like mechanical properties, were precipitated through a detailed understanding of the natural silk spinning process, which begins in the silk gland located in the spider abdomen [4,69]. Along these lines, recent efforts towards improving mussel-inspired materials are aimed at achieving an improved biological, physical and chemical understanding of byssus formation $[32,70,71]$. In the final section of this review, we provide a brief overview of the current understanding of the natural byssus bio-fabrication process.

\subsection{The mussel foot}

Byssal thread formation takes place in the mussel foot, a tongue-shaped organ, which extends out of the shell 3 to 4 times its initial length to form threads on the surrounding substrate (Fig. 3A) [71-73]. Three different glands have been identified within the foot in which the various byssus proteins are synthesized and stockpiled prior to secretion. The glands were identified over 40 years ago via histology and electron microscopy revealing high content of secretory vesicles with distinct shapes and sizes, acquiring a range of different names due to their appearance and proposed contents of the vesicles [73-78]. Here, we utilize a more recent nomenclature, naming them according to the parts of the byssus they produce - i.e. the core, cuticle and plaque gland [71]. 
During the formation process, protein vesicles from the glands are secreted into a small trench along the top of the foot called the ventral groove forming the main part of thread (Fig. 3B) [71-73]. The groove terminates in a small divot called the distal depression where the plaque is formed. This process superficially resembles polymer injection molding, a process used to bring polymer melts into a desired morphology [71-73]. The entire assembly process lasts 3-5 minutes, during which the secreted protein vesicles self-organize into the byssal thread complete with its highly complex micro and nanoarchitecture, which is afterwards released from the groove (Fig. 3B). Considering that this process takes place under ambient conditions, byssus fabrication has become an important role model for sustainable polymer processing. It is proposed that during assembly, secretory vesicles undergo a fluid-to-fiber transition due to a change in $\mathrm{pH}$ and salt concentration [11, 12]. For example, a pH low as 2 was measured in the plaque secretion during the formation process, which dramatically increases to $\mathrm{pH} 8$ of sea water after the thread is released [79].

It is extremely challenging to track this dynamic formation process in vivo as it occurs in the groove hidden from view. To overcome this challenge, researchers developed a protocol to induce secretion of protein vesicles via injection of a $0.56 \mathrm{M} \mathrm{KCl}$ solution into the base of the foot where the pedal nerve center sits [76]. Following induction, a fibrous structure can be detected in the groove which was further analyzed using several techniques $[70,71,76]$. While this so-called induced thread is morphologically impaired due to the harsh $\mathrm{KCl}$ injection, which paralyzes the mussel foot, it provides a means of studying the aspects of byssus formation that depend on spontaneous self-assembly $[70,71,80]$. Indeed, certain structural features similar to the native thread are achieved via induction, indicating that self-assembly drives much of the formation process [71]. Below, we will describe the details of the core, cuticle and plaque formation individually. 

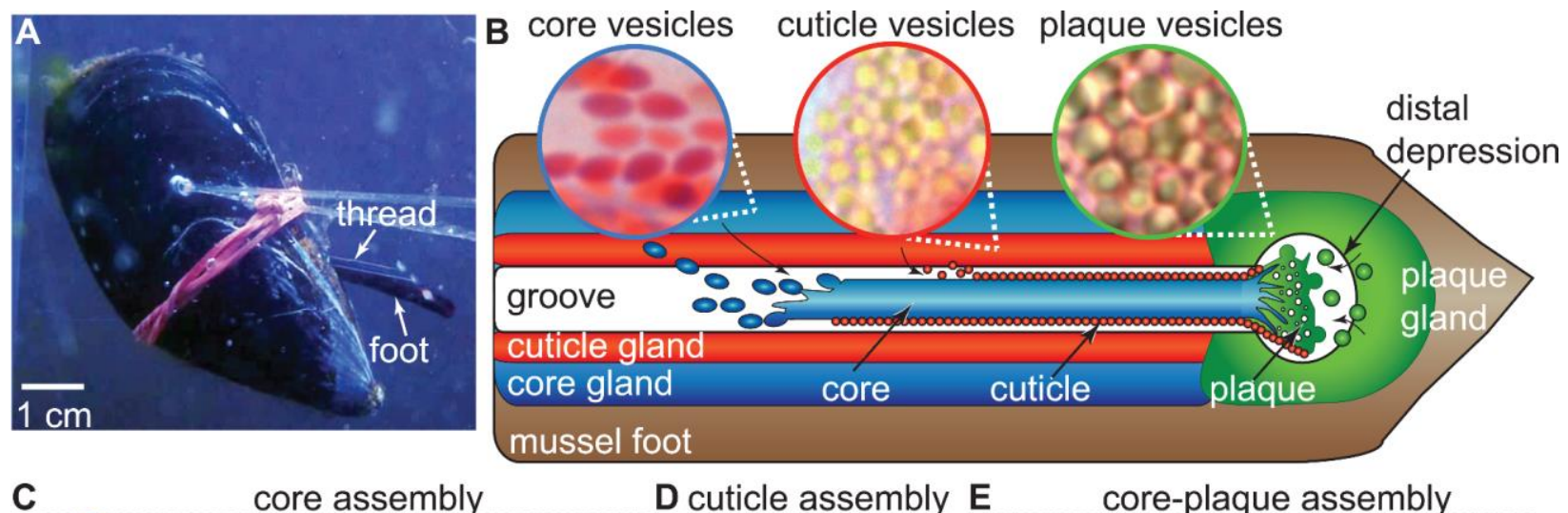

D cuticle assembly
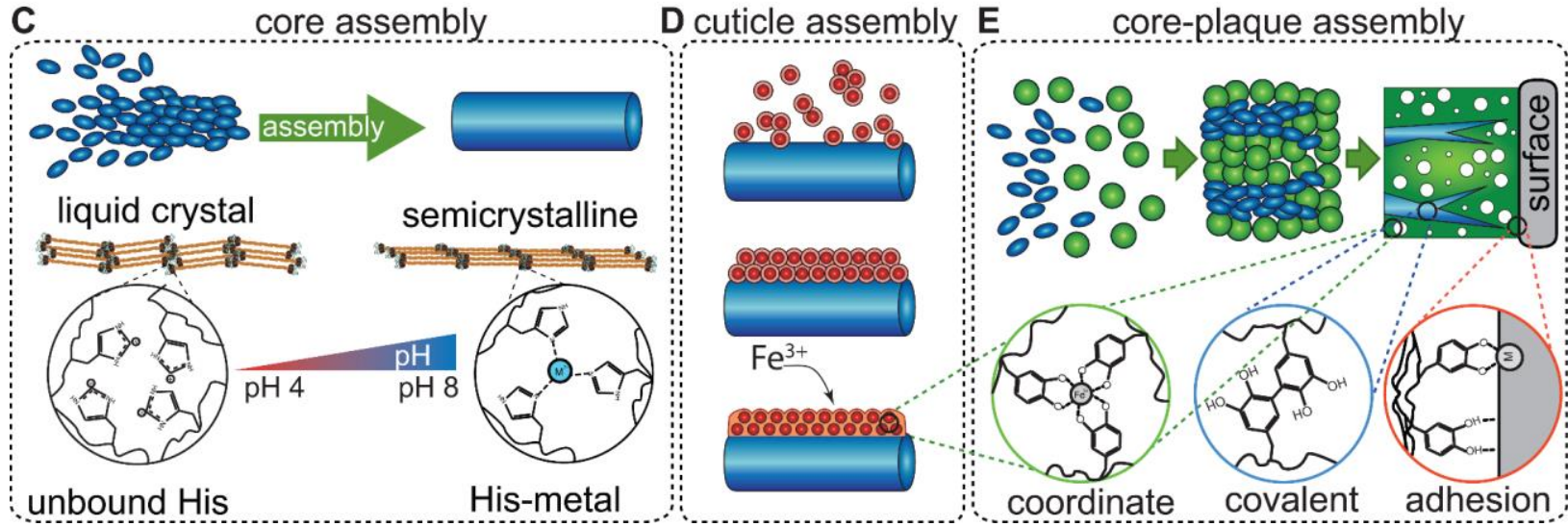

Figure 3. Schematic summary of byssus formation. A) Each byssal thread is individually created by the mussel foot organ. B) Byssus proteins are stored in the foot within secretory vesicles in specific glands in the foot, and secreted into the groove and distal depression where they self-assemble into a new thread. C) PreCols are stored in core vesicles as a liquid crystal phase. Self-assembly to a semicrystalline fiber is likely initiated via a pH trigger. D) Cuticle vesicles self-organize into a thin layer on the assembled core and are later cross-linked via DOPA-metal coordination. E) The plaque-core interface self-assembles into a complex root-like interface. DOPA-rich proteins in the plaque utilize a range of different interactions to mediate adhesion and cohesion. 


\subsection{Core formation}

The proteins comprising the core are produced by the largest gland located along almost the entire mussel foot. The core gland was initially named the white gland due to its coloration and later named the collagen gland due to histological evidence of collagenous proteins in the secretory vesicles $[74,75]$. The secretory vesicles have an ellipsoidal shape with a long axis of $1-2 \mu \mathrm{m}$ (Fig. 3B). Core vesicles exhibit a characteristic banding pattern in TEM and show birefringence under polarized light, leading researchers to speculate that preCols are stored in a smectic liquid crystal phase, aligned like books on a shelf $[16,40,77,81]$. This pre-packing of proteins is believed to contribute to formation of the semi-crystalline alignment in the native thread (Fig. 3C) [16, 71]. Self-assembly of the core vesicles in induced threads showed alignment of proteins on the scale of hundreds of microns, but not on the centimeter-scale as observed in native threads. This suggests that biologically controlled processes, such as mechanical drawing, might be important to achieve higher order alignment [71]. In addition, the thread matrix proteins PTMP-1 has been shown to exhibit a clear influence on the morphology and higher order organization of collagen fibrils in vitro[22, 82], suggesting an important role in guiding the formation process of the native thread core.

Raman spectroscopic investigation of the core vesicle proteins revealed that the secondary structure resembles type I collagen and barely changes shortly after induced assembly. However, comparison between induced and native threads show certain differences, which may arise from post-processing [71]. It is still unclear how the liquid crystal protein phase transitions to a solid semi-crystalline fiber. One strong hypothesis supported by studies of HRD peptides (section 3.3) is that the $\mathrm{pH}$ increase going from secretory vesicle to seawater induces a conformational transition of the HRDs leading to aggregation and assembly, which is initiated by the deprotonation of Histidine (pKa 6.5) (Fig. 3C) [65, 66]. Notably, histidine deprotonation also promotes metal binding, which is well-established to contribute to the mechanical performance of the thread $[11,17]$ (section 2.2 ). It has been further hypothesized that evolutionary 
conserved Tyr residues at the ends of preCol proteins are converted to DOPA, which becomes oxidized at the high $\mathrm{pH}$ of seawater, forming covalent crosslinks between the ends of neighboring preCols.

\subsection{Cuticle formation}

The cuticle is formed via secretion of the vesicles from the cuticle gland following core formation. Although it was initially suggested that the vesicles in the cuticle gland contain enzymes such as catechol oxidase (leading to the name enzyme gland) [83], Zuccarello demonstrated the gland contains DOPA-rich proteins secreted as a protective outer cuticle for the core, after which it was renamed the accessory gland $[73,78]$. The protein vesicles in the cuticle gland possess a distinctive mottled internal structure $[76$, 78], which is partially retained in the granules of the byssus cuticle (Fig. 1D) [15, 28]. In induced threads, the cuticle vesicles aggregate in the groove and then form a thin layer on top of the already assembled core (Fig. 3D) $[71,76]$. These data suggest that the cuticle vesicle contents, known to contain mfp- 1 , possess a low surface tension, which is consistent with the tendency of recombinant mfp-1 to form coacervates [35].

Metal coordination mediated by DOPA residues in $\mathrm{mfp}-1$ is responsible for the hardness and stiffness of the cuticle $[28,29]$ and was also suggested to be necessary for the assembly process, guiding early efforts towards mussel-inspired polymers [37]. However, recent in situ investigations of cuticle assembly using Raman spectroscopy showed no evidence of DOPA-metal coordination, leading to the hypothesis that metal ions are likely infiltrated in a later step after assembly of thread hierarchical structure [71]. The source of the metal ions remains elusive - on one hand, metal ions from the sea water could passively infiltrate the byssal thread after its release, as shown in vitro in metal-depleted threads [28, 29] and on the other hand, metals acquired from seawater could be stored in the filter feeding mussel and actively secreted during byssus assembly. The second hypothesis is supported by studies that tracked uptake of radioactively labeled metal ions taken up into mussel tissue, which inevitably ended up in the byssus after mussels were placed in fresh seawater [84]. Regardless of the mechanism, infiltration and coordination 
of metal ions after the structure is already formed shows that metal ions are not necessary for the assembly process [71]. This is highly relevant to current efforts to produce mussel-inspired metallopolymeric materials, most of which mix the polymer together with the metals and then induce assembly by raising $\mathrm{pH}[6,37]$.

\subsection{Plaque formation}

The plaque is composed of at least 5 different proteins which function in certain parts of the plaque; however, as described above, the main players at the adhesive interface are mfp-3 and mfp-5 [7, 12]. These proteins are stored in round vesicles $(d=1-2 \mu \mathrm{m})$ in the plaque gland in the distal region of the foot. Since the proteins contain a high percentage of DOPA residues, the plaque gland was formerly known as the phenol gland $[74,75]$. Protein vesicles in the plaque gland are secreted via a complex system of small channels called longitudinal ducts [76] in a temporally regulated fashion by which certain proteins responsible for interfacial adhesion are secreted first, whereas others follow later [70]. The complex micro- and nano-porous structure of the plaque is observed shortly after induced secretion, suggesting a quick and dramatic transition from a dense, fluid protein phase to an open-cell foam (Fig. 3B and E) [71, 80]. It has been suggested that the adhesive proteins are stored as coacervates, which then spontaneously transition to a solid due to the local physiochemical environment ( $\mathrm{pH}$, salt concentration) $[12,71]$. As mentioned, coacervates are dense liquid-liquid phase separations, possessing a low interfacial energy, which allows them to spread over surfaces, enhancing adhesion. Specific variants of purified mfp-3, for example, have been demonstrated to self-coacervate, dependent on a combination of hydrophobic and electrostatic forces achieved by balancing $\mathrm{pH}$ and ionic strength[49]. Similarly, a recombinant form of the cuticle protein mfp-1 lacking DOPA was also discovered to self-coacervate under appropriate conditions of $\mathrm{pH}$ and ionic strength, which was proposed to be mediated via cation-pi interactions between tyrosine and lysine residues[35]. While these in vitro demonstrations of the ability of plaque and cuticle proteins (or their analogs) to form liquid-liquid phase separations provide compelling reason to believe that 
coacervates contribute to byssus formation, their presence and role in vivo remains to be demonstrated during natural formation.

Interestingly, during thread formation, the plaque proteins and core proteins do not mix, but rather spontaneously form a complex interface where the thread core protrudes into the plaque resembling a root-like structure [71]. Storage of proteins in dense coacervates (plaque) and liquid crystals (core) is suggested to be critical for this process. As in the other byssal thread parts, complex crosslinking of the proteins eventually leads to the transition of the liquid precursor to the solid material, proposed to occur via DOPA-metal coordination, as well as oxidation driven covalent bond formation $[71,80]$. An essential part of this is the redox control of DOPA-residues in the plaque proteins, which is proposed to be enhanced by $\mathrm{mfp}-6$, a cysteine-rich protein $[12,32]$.

\subsection{Extracted principles}

To summarize, the current understanding of mussel byssal thread assembly highlights three important factors that facilitate rapid assembly of complex hierarchically structured fibers 1 ) stimuli responsive behavior of the protein building blocks 2) control of microenvironment via vesicles 3 ) triggered assembly in response to changing local conditions. In this way, the mussel is able to store large amounts of fluid precursor at high concentrations by simple physicochemical controls $(\mathrm{pH}$, ionic strength, redox conditions). These parameters are apparently tuned to bring the proteins into liquid crystal and complex coacervate phases, which contribute to the attainment of semicrystalline order and enhanced adhesive spreading, respectively. During secretion, the transition to seawater conditions induces controlled aggregation of the stimuli-responsive protein precursors, which due to their protein sequence, respond to changes in $\mathrm{pH}$ and ionic strength with altered conformation and cross-linking capacity. These crucial factors could be readily transferred into bio-inspired production processes via both synthetic chemistry and biotechnology, with promise for sustainable fabrication of high performance polymers.

\section{Conclusions}


Proteinaceous biopolymeric materials such as silk and mussel byssus are important role models for inspiring sustainable production of next generation advanced polymers. In particular, byssus has already spawned many mussel-inspired materials and glues, which tap into the metal coordination chemistry of the byssal threads to achieve wet adhesion, self-healing capacity and high toughness [6-8]. While much of this success has been achieved through a reductionist approach via synthetic chemistry, biotechnological approaches are increasingly important as they permit researchers to more closely mimic the complex biochemistry, and thus, multi-scale structure of the native material. Indeed, it has been clearly demonstrated that the biochemical context of the natural protein sequences of the byssal proteins is critical for material performance. As demonstrated in efforts to produce artificial recombinant silk fibers with native properties, a biotechnological approach for producing mussel-inspired polymers must be coupled with a deep understanding of the natural byssus fabrication process [4,69]. Recent investigations in this direction have highlighted the importance of stimuli responsive protein sequences, controlled microenvironments and physicochemical assembly triggers $[12,71]$, all of which can readily be transferred to the lab bench via biotechnological approaches. However, this will likely require appropriate technology development to mimic this complex fabrication process, which is perhaps most closely approximated with microfluidic devices and 3D printing. While much remains to be done, the outlook for biotechnological production of mussel-inspired materials is very positive.

\section{Acknowledgement}

The authors acknowledge financial support from the Max Planck Society, the German Research Foundation (DFG), and Natural Sciences and Engineering Research Council of Canada (NSERC Discovery Grant RGPIN-2018-05243).

\section{Conflict of interest}

The authors declare no financial or commercial conflict of interest. 


\section{References}

[1] Baer, A., Schmidt, S., Haensch, S., Eder, M., Mayer, G., Harrington, M. J., Mechanoresponsive lipidprotein nanoglobules facilitate reversible fibre formation in velvet worm slime. Nat. Comms. 2017, 8, 974. [2] Gosline, J., Lillie, M., Carrington, E., Guerette, P., Ortlepp, C., Savage, K., Elastic proteins: biological roles and mechanical properties. Philos. Trans. R. Soc. London, Ser. B 2002, 357, 121-132.

[3] Harrington, M. J., Speck, O., Speck, T., Wagner, S., Weinkamer, R., Biological archetypes for self-healing materials, Adv.Polym. Sci., Springer Berlin Heidelberg, Berlin, Heidelberg 2016.

[4] Heim, M., Keerl, D., Scheibel, T., Spider silk: from soluble protein to extraordinary fiber. Angew. Chem. Int. Ed. 2009, 48, 3584-3596.

[5] Picken, S. J., Sikkema, D. J., Boerstoel, H., Dingemans, T. J., van der Zwaag, S., Liquid crystal main-chain polymers for high-performance fibre applications. Liq. Cryst. 2011, 38, 1591-1605.

[6] Krogsgaard, M., Nue, V., Birkedal, H., Mussel-inspired materials: self-healing through coordination chemistry. Chem. Eur. J. 2016, 22, 844-857.

[7] Lee, B. P., Messersmith, P. B., Israelachvili, J. N., Waite, J. H., Mussel-inspired adhesives and coatings, Annu. Rev. Mater. Res., Vol 41 2011, pp. 99-132.

[8] Li, L., Smitthipong, W., Zeng, H., Mussel-inspired hydrogels for biomedical and environmental applications. Polym. Chem. 2015, 6, 353-358.

[9] Carrington, E., Waite, J. H., Sara, G., Sebens, K. P., Mussels as a model system for integrative ecomechanics, in: Carlson, C. A., Giovannoni, S. J. (Eds.), Annu. Rev. Mar. Sci., Vol 7 2015, pp. 443-469.

[10] DeMartini, D. G., Errico, J. M., Sjoestroem, S., Fenster, A., Waite, J. H., A cohort of new adhesive proteins identified from transcriptomic analysis of mussel foot glands. J. R. Soc. Interface 2017, 14, 20170151.

[11] Degtyar, E., Harrington, M. J., Politi, Y., Fratzl, P., The mechanical role of metal ions in biogenic protein-based materials. Angew. Chem. Int. Ed. 2014, 53, 12026-12044.

[12] Waite, J. H., Mussel adhesion - essential footwork. J. Exp. Biol. 2017, 220, 517-530.

[13] Reinecke, A., Bertinetti, L., Fratzl, P., Harrington, M. J., Cooperative behavior of a sacrificial bond network and elastic framework in providing self-healing capacity in mussel byssal threads. J. Struct. Biol. 2016, In Press, doi:10.1016/j.jsb.2016.1007.1020.

[14] Carrington, E., Gosline, J., Mechanical design of mussel byssus: Load cycle and strain rate dependence. Amer. Malacol. Bull. 2004, 18, 135-142.

[15] Holten-Andersen, N., Fantner, G. E., Hohlbauch, S., Waite, J. H., Zok, F. W., Protective coatings on extensible biofibres. Nat. Mater. 2007, 6, 669-672.

[16] Krauss, S., Metzger, T. H., Fratzl, P., Harrington, M. J., Self-repair of a biological fiber guided by an ordered elastic framework. Biomacromolecules 2013, 14, 1520-1528.

[17] Schmitt, C. N. Z., Politi, Y., Reinecke, A., Harrington, M. J., Role of sacrificial protein-metal bond exchange in mussel byssal thread self-healing. Biomacromolecules 2015, 16, 2852-2861.

[18] Harrington, M. J., Waite, J. H., Holdfast heroics: comparing the molecular and mechanical properties of Mytilus californianus byssal threads. J. Exp. Biol. 2007, 210, 4307-4318.

[19] Harrington, M. J., Gupta, H. S., Fratzl, P., Waite, J. H., Collagen insulated from tensile damage by domains that unfold reversibly: In situ X-ray investigation of mechanical yield and damage repair in the mussel byssus. J. Struct. Biol. 2009, 167, 47-54.

[20] Waite, J. H., Qin, X. X., Coyne, K. J., The peculiar collagens of mussel byssus. Matrix Biol. 1998, 17, 93106.

[21] Sagert, J., Waite, J. H., Hyperunstable matrix proteins in the byssus of Mytilus galloprovincialis. J. Exp. Biol. 2009, 212, 2224-2236.

[22] Suhre, M. H., Gertz, M., Steegborn, C., Scheibel, T., Structural and functional features of a collagenbinding matrix protein from the mussel byssus. Nat. Comms. 2014, 5. 
[23] Sun, C., Lucas, J. M., Waite, J. H., Collagen-binding matrix proteins from elastomeric extraorganismic byssal fibers. Biomacromolecules 2002, 3, 1240-1248.

[24] Arnold, A. A., Byette, F., Seguin-Heine, M. O., LeBlanc, A., Sleno, L., Tremblay, R., Pellerin, C., Marcotte, I., Solid-state NMR structure determination of whole anchoring threads from the blue mussel Mytilus edulis. Biomacromolecules 2013, 14, 132-141.

[25] Hagenau, A., Papadopoulos, P., Kremer, F., Scheibel, T., Mussel collagen molecules with silk-like domains as load-bearing elements in distal byssal threads. J. Struct. Biol. 2011, 175, 339-347.

[26] Vaccaro, E., Waite, J. H., Yield and post-yield behavior of mussel byssal thread: a self-healing biomolecular material. Biomacromolecules 2001, 2, 906-911.

[27] Hwang, D. S., Waite, J. H., Three intrinsically unstructured mussel adhesive proteins, mfp-1, mfp-2, and mfp-3: Analysis by circular dichroism. Protein Sci. 2012, 21, 1689-1695.

[28] Harrington, M. J., Masic, A., Holten-Andersen, N., Waite, J. H., Fratzl, P., Iron-clad fibers: a metalbased biological strategy for hard flexible coatings. Science 2010, 328, 216-220.

[29] Schmitt, C. N. Z., Winter, A., Bertinetti, L., Masic, A., Strauch, P., Harrington, M. J., Mechanical homeostasis of a DOPA-enriched biological coating from mussels in response to metal variation. . J. R. Soc. Interface 2015, 12.

[30] Lu, Q. Y., Danner, E., Waite, J. H., Israelachvili, J. N., Zeng, H. B., Hwang, D. S., Adhesion of mussel foot proteins to different substrate surfaces. . J. R. Soc. Interface 2013, 10.

[31] Lee, H., Scherer, N. F., Messersmith, P. B., Single-molecule mechanics of mussel adhesion. Proc. Natl. Acad. Sci. U.S.A. 2006, 103, 12999-13003.

[32] Yu, J., Wei, W., Danner, E., Ashley, R. K., Israelachvili, J. N., Waite, J. H., Mussel protein adhesion depends on interprotein thiol-mediated redox modulation. Nat. Chem. Biol. 2011, 7, 588-590.

[33] Maier, G. P., Rapp, M. V., Waite, J. H., Israelachvili, J. N., Butler, A., Adaptive synergy between catechol and lysine promotes wet adhesion by surface salt displacement. Science 2015, 349, 628-632.

[34] Gebbie, M. A., Wei, W., Schrader, A. M., Cristiani, T. R., Dobbs, H. A., Idso, M., Chmelka, B. F., Waite, J. H., Israelachvili, J. N., Tuning underwater adhesion with cation-pi interactions. Nat. Chem. 2017, 9, 473479.

[35] Kim, S., Yoo, H. Y., Huang, J., Lee, Y., Park, S., Park, Y., Jin, S., Jung, Y. M., Zeng, H., Hwang, D. S., Jho, Y., Salt triggers the simple coacervation of an underwater adhesive when cations meet aromatic pi electrons in seawater. ACS Nano 2017, 11, 6764-6772.

[36] Fullenkamp, D. E., He, L., Barrett, D. G., Burghardt, W. R., Messersmith, P. B., Mussel-inspired histidine-based transient network metal coordination hydrogels. Macromolecules 2013, DOI: 10.1021/ma301791n.

[37] Holten-Andersen, N., Harrington, M. J., Birkedal, H., Lee, B. P., Messersmith, P. B., Lee, K. Y. C., Waite, J. $\mathrm{H}$., $\mathrm{pH}$-induced mussel metal-ligand cross-links yield self-healing polymer networks with near-covalent elastic moduli. Proc. Natl. Acad. Sci. U.S.A. 2011, 108, 2651-2655.

[38] Enke, M., Jehle, F., Bode, S., Vitz, J., Harrington, M. J., Hager, M. D., Schubert, U. S., Histidine-zinc interactions investigated by isothermal titration calorimetry (ITC) and their application in self-healing polymers. Macromolec. Chem. Phys. 2017, 218, 1600458.

[39] Grindy, S. C., Holten-Andersen, N., Bio-inspired metal-coordinate hydrogels with programmable viscoelastic material functions controlled by longwave UV light. Soft Matter 2017, 13, 4057-4065.

[40] Harrington, M. J., Waite, J. H., pH-dependent locking of giant mesogens in fibers drawn from mussel byssal collagens. Biomacromolecules 2008, 9, 1480-1486.

[41] Harrington, M. J., Waite, J. H., How nature modulates a fiber's mechanical properties: mechanically distinct fibers drawn from natural mesogenic block copolymer variants. Adv. Mater. 2009, 21, 440-444.

[42] Byette, F., Laventure, A., Marcotte, I., Pellerin, C., Metal-ligand interactions and salt bridges as sacrificial bonds in mussel byssus-derived materials. Biomacromolecules 2016, 17, 3277-3286. 
[43] Byette, F., Pellerin, C., Marcotte, I., Self-assembled pH-responsive films prepared from mussel anchoring threads. J. Mater. Chem. B 2014, 2, 6378-6386.

[44] Montroni, D., Piccinetti, C., Fermani, S., Calvaresi, M., Harrington, M. J., Falini, G., Exploitation of mussel byssus mariculture waste as a water remediation material. RSC Advances 2017, 7, 36605-36611.

[45] Montroni, D., Valle, F., Rapino, S., Fermani, S., Calvaresi, M., Harrington, M. J., Falini, G., Functional biocompatible matrices from mussel byssus waste. ACS Biomater. Sci. Eng. 2018, 4, 57-65.

[46] Strausberg, R. L., Anderson, D. M., Filpula, D., Finkelman, M., Link, R., McCandliss, R., Orndorff, S. A., Strausberg, S. L., Wei, T., Development of a microbial system for production of mussel adhesive protein ACS Sympos. Ser. 1989, 385, 462-464.

[47] Papov, V. V., Diamond, T. V., Biemann, K., Waite, J. H., Hydroxyarginine containing polyphenolic proteins in the adhesive plaques of the marine mussel Mytilus edulis. J. Biol. Chem. 1995, 270, 2018320192.

[48] Waite, J. H., Qin, X. X., Polyphosphoprotein from the adhesive pads of Mytilus edulis. Biochemistry 2001, 40, 2887-2893.

[49] Wei, W., Tan, Y., Rodriguez, N. R. M., Yu, J., Israelachvili, J. N., Waite, J. H., A mussel-derived one component adhesive coacervate. Acta Biomater. 2014, 10, 1663-1670.

[50] Golser, A. V., Scheibel, T., Biotechnological production of the mussel byssus derived collagen preColD. RSC Advances 2017, 7, 38273-38278.

[51] Yoo, H. Y., Song, Y. H., Foo, M., Seo, E., Hwang, D. S., Seo, J. H., Recombinant mussel proximal thread matrix protein promotes osteoblast cell adhesion and proliferation. BMC Biotechnol. 2016, 16.

[52] Kim, B. J., Cheong, H., Hwang, B. H., Cha, H. J., Mussel-inspired protein nanoparticles containing iron(III)-DOPA complexes for pH-responsive drug delivery. Angew. Chem. Int. Ed. 2015, 54, 7318-7322.

[53] Kim, B. J., Oh, D. X., Kim, S., Seo, J. H., Hwang, D. S., Masic, A., Han, D. K., Cha, H. J., Mussel-mimetic protein-based adhesive hydrogel. Biomacromolecules 2014, 15, 1579-1585.

[54] Zeng, H., Hwang, D. S., Israelachvili, J. N., Waite, J. H., Strong reversible Fe3+-mediated bridging between dopa-containing protein films in water. Proc. Natl. Acad. Sci. U.S.A. 2010, 107, 12850-12853.

[55] Kim, S., Huang, J., Lee, Y., Dutta, S., Yoo, H. Y., Jung, Y. M., Jho, Y., Zeng, H., Hwang, D. S., Complexation and coacervation of like-charged polyelectrolytes inspired by mussels. Proc. Natl. Acad. Sci. U.S.A. 2016, 113, E847-E853.

[56] Hwang, D. S., Gim, Y., Kang, D. G., Kim, Y. K., Cha, H. J., Recombinant mussel adhesive protein Mgfp5 as cell adhesion biomaterial. J. Biotechnol. 2007, 127, 727-735.

[57] Kim, C. S., Choi, Y. S., Ko, W., Seo, J. H., Lee, J., Cha, H. J., A mussel adhesive protein fused with the BC domain of protein $A$ is a functional linker material that efficiently immobilizes antibodies onto diverse surfaces. Adv. Func. Mater. 2011, 21, 4101-4108.

[58] Choi, B.-H., Cheong, H., Jo, Y. K., Bahn, S. Y., Seo, J. H., Cha, H. J., Highly purified mussel adhesive protein to secure biosafety for in vivo applications. Microbial Cell Factories 2014, 13.

[59] Hwang, D. S., Gim, Y., Yoo, H. J., Cha, H. J., Practical recombinant hybrid mussel bloadhesive fp-151. Biomaterials 2007, 28, 3560-3568.

[60] Kim, B. J., Choi, Y. S., Cha, H. J., Reinforced multifunctionalized nanofibrous scaffolds using mussel adhesive proteins. Angew. Chem. Int. Ed. 2012, 51, 675-678.

[61] Hwang, D. S., Sim, S. B., Cha, H. J., Cell adhesion biomaterial based on mussel adhesive protein fused with RGD peptide. Biomaterials 2007, 28, 4039-4046.

[62] Choi, B.-H., Choi, Y. S., Kane, D. G., Kim, B. J., Song, Y. H., Cha, H. J., Cell behavior on extracellular matrix mimic materials based on mussel adhesive protein fused with functional peptides. Biomaterials 2010, 31, 8980-8988.

[63] Lim, S., Choi, Y. S., Kang, D. G., Song, Y. H., Cha, H. J., The adhesive properties of coacervated recombinant hybrid mussel adhesive proteins. Biomaterials 2010, 31, 3715-3722. 
[64] Yang, B., Ayyadurai, N., Yun, H., Choi, Y. S., Hwang, B. H., Huang, J., Lu, Q. Y., Zeng, H. B., Cha, H. J., In vivo residue-specific Dopa-incorporated engineered mussel bioglue with enhanced adhesion and water resistance. Angew. Chem. Int. Ed. 2014, 53, 13360-13364.

[65] Jehle, F., Fratzl, P., Harrington, M. J., Metal-tunable self-assembly of hierarchical structure in musselinspired peptide films. ACS Nano 2018, 12, 2160-2168.

[66] Reinecke, A., Brezesinski, G., Harrington, M. J., pH-responsive self-organization of metal-binding protein motifs from biomolecular junctions in mussel byssus Adv. Mater. Interfaces 2017, 4, 1600416.

[67] Wei, W., Petrone, L., Tan, Y., Cai, H., Israelachvili, J. N., Miserez, A., Waite, J. H., An Underwater Surface-Drying Peptide Inspired by a Mussel Adhesive Protein. Adv. Func. Mater. 2016, 26, 3496-3507.

[68] Wei, W., Yu, J., Gebbie, M. A., Tan, Y., Rodriguez, N. R. M., Israelachvili, J. N., Waite, J. H., Bridging Adhesion of Mussel-Inspired Peptides: Role of Charge, Chain Length, and Surface Type. Langmuir 2015, 31, 1105-1112.

[69] Heidebrecht, A., Eisoldt, L., Diehl, J., Schmidt, A., Geffers, M., Lang, G., Scheibel, T., Biomimetic fibers made of recombinant spidroins with the same toughness as natural spider silk. Adv. Mater. 2015, 27, 2189-2194.

[70] Petrone, L., Kumar, A., Sutanto, C. N., Patil, N. J., Kannan, S., Palaniappan, A., Amini, S., Zappone, B., Verma, C., Miserez, A., Mussel adhesion is dictated by time-regulated secretion and molecular conformation of mussel adhesive proteins. Nat. Comms. 2015, 6.

[71] Priemel, T., Degtyar, E., Dean, M. N., Harrington, M. J., Rapid self-assembly of complex biomolecular architectures during mussel byssus biofabrication. Nat. Comms. 2017, 8.

[72] Silverman, H. G., Roberto, F. F., Byssus formation in Mytilus, Biological adhesive systems: From nature to technical and medical application, Springer 2010, pp. 273-283.

[73] Waite, J. H., The formation of mussel byssus: anatomy of a natural manufacturing process. Results Probl. Cell Differ. 1992, 19, 27-54.

[74] Brown, C. H., Some structural proteins of Mytilus edulis. J. Cell Sci. 1952, 93, 487-502.

[75] Pujol, J. P., Formation of byssus in common mussel (Mytilus edulis). Nature 1967, 214, 204-205.

[76] Tamarin, A., Keller, P. J., Ultrastructural study of byssal thread forming system in Mytilus. J. Ultrastruct. Res. 1972, 40, 401-416.

[77] Vitellaro-Zuccarello, L., The collagen gland of Mytilus galloprovincialis: an ultrastructural and cytochemical study on secretory granules. J. Ultrastruct. Res. 1980, 73, 135-147.

[78] Vitellaro-Zuccarello, L., Ultrastructural and cytochemical study on the enzyme gland of the foot of a mollusk. Tissue Cell 1981, 13, 701-713.

[79] Rodriguez, N. R. M., Das, S., Kaufman, Y., Israelachvili, J. N., Waite, J. H., Interfacial pH during mussel adhesive plaque formation. Biofouling 2015, 31, 221-227.

[80] Filippidi, E., DeMartini, D. G., de Molina, P. M., Danner, E. W., Kim, J., Helgeson, M. E., Waite, J. H., Valentine, M. T., The microscopic network structure of mussel (Mytilus) adhesive plaques. J. R. Soc. Interface 2015, 12.

[81] Hassenkam, T., Gutsmann, T., Hansma, P., Sagert, J., Waite, J. H., Giant bent-core mesogens in the thread forming process of marine mussels. Biomacromolecules 2004, 5, 1351-1354.

[82] Yoo, H. Y., Huang, J., Li, L., Foo, M., Zeng, H. B., Hwang, D. S., Nanomechanical contribution of collagen and von Willebrand factor $A$ in marine underwater adhesion and its implication for collagen manipulation. Biomacromolecules 2016, 17, 946-953.

[83] Smyth, J. D., A technique for the histochemical demonstration of polyphenol oxidase and its application to egg-shell formation in helminths and byssus formation in Mytilus. Q. J. Microsc. Sci. 1954, 95, 139-152.

[84] George, S. G., Pirie, B. J. S., Coombs, T. L., Kinetics of accumulation and excretion of ferric hydroxide in Mytilus edulis (L) and its distribution in tissues. J. Exp. Mar. Biol. Ecol. 1976, 23, 71-84. 